\title{
Effects of Poor-Reading Culture on Distance Education Students' Academic Performance at Kwame Nkrumah University in Zambia
}

\author{
Hachintu Joseph Kayuni, PhD. \\ Department of Quality Assurance, Kwame Nkrumah University, Kabwe - Zambia
}

\begin{abstract}
This article reports a study undertaken in August 2016 to examine the effects of poor reading culture among the Distance Education students at Kwame Nkrumah University in Zambia. Like in many other universities, students under Distance Education Programme at this institution mainly learn through modules as their indispensible tool, though sometimes there has been moments, such as during Residential Schools when contiguous learning ( face-to-face) has taken place. Because of this, this article regards one's ability to read as a crucial requirement; just like one's comprehension skills are of paramount importance if one is to make it in this module-driven mode of learning. My central contention in this article, therefore, is that a sound reading culture is an essential prerequisite in any student involved in a form of learning that makes use of modules.
\end{abstract}

In examining the culture of reading among students, the article has assessed the claim that there has been deterioration in the reading habits among students of the current generation which has impacted negatively on their academic performance. The causes of poor-reading culture among Kwame Nkrumah University students have been analysed and the results from this study reveal the effects of students' poor reading background on academic performance. Such common effects as students' indecent behaviour and use of corruption have been discussed, where, for instance, knowing too well that they have not read the modules, and with their desperation to pass their coursework and exams, some students resort to such indecent habits as offering themselves to their lecturers for sex in exchange for marks, while others opt for the corrupt acts of buying marks from lecturers and hiring people to write their assignments and research projects on their behalf.

The article concludes with a suggestion that a fair consideration be given to the effects of poor reading culture whenever addressing the common challenges of students involving themselves in indecent and corrupt ways of obtaining academic favour from lecturers, a vice that seems to have marred many institutions of higher learning in Zambia today.

Keywords: Reading Culture, Distance Education, Module, Academic Performance, Exam, Indecent Behavior, Corruption.

\section{INTRODUCTION}

This article investigates the effects of the poor reading culture among Distance Education Students at Kwame Nkrumah University in Zambia, a study that took place between August $15^{\text {th }}$ and September $9^{\text {th }} 2016$.

Lewis and Spencer refer to 'Open Learning' as a term used to describe courses flexibly designed to meet individual (learner) requirements. ${ }^{1}$ The duo contend that not only is this mode of learning applied to provisions which try to remove barriers that prevent attendances at more traditional courses, but it also suggests a learner-centred philosophy. Though in principal the delivery of courses for Distance students at Kwame Nkrumah University has been done through distance mode using modules which students are expected to read at home, there has been also a good deal of the Contiguous (face-to-face) mode, as the case often turns out to be during the so-called ' Campus-based residential schooling'.

The Directorate of Open and Distance Learning ( DODL) at the institution has put in place support services which counsel and advise students on what to study, as well as their progress during the study. As a way of trying to alleviate the challenges students face while studying at home, the Directorate through its Learner-support department has opened up ten learner-support centres; one in each of the ten provinces in the country. This initiative was meant to provide support to students from 
a variety of sources including professional (tutors, counselors) and peers (mentors, friends) at a variety of places and times. The principal behind this initiative is simple: to move away from an arrangement where services for students under distance learning arrangement are only available in a local centre and at stipulated times. To ensure flexibility even in terms of communication, the Department of Learner Support has utilised various roots which include face-to-face, letter, telephone and electronic means. The idea behind this arrangement is that the student will, to a large extent, benefit from the distance mode, through utilisation of modules as their indispensable tool. In this regard, one's ability to read (literacy) becomes a crucial requirement; just like one's comprehension skills are of paramount importance if one is to make it in this mode of learning. In this article, my central contention is that a sound reading culture is an essential prerequisite in a student involved in a form of learning that makes use of modules.

\section{LITERATURE REVIEW}

A study carried out by Henry P. ${ }^{2}$ in Nigeria reveals that 40 percent of adult Nigerians never read a non-fiction book from cover to cover after they finish school. According to the findings of the study, the average Nigerian reads less than one book per year, and only one percent of successful men and women in Nigeria read one non-fiction book per month. The same study showed that 30 million Nigerians have graduated from high school with poor reading skills. Some Nigerians may not read because they are not working in the right field(s). Writing on the same subject of poor reading habits among Nigerians, Aina et al ${ }^{3}$ observe that "if regular reading and studying is a required condition of one's job or profession, this in effect means one needs to read, even if it is under duress". According to them, this is because the magnitude of poor culture of reading jeopardizes the future of schools. They observe that what is most frustrating is the fact that much of the so-called reading problem can be prevented if government, libraries, and teachers apply what is known as reading instruction or techniques. With the vast majority of the world's information today not being digitized, but instead in the print form and mostly in books, one may wonder as to whether reading, especially among adults is on the wane. A scholar by the name of Okebukola ${ }^{4}$ observes that communications with words will still thrive, but in a new format and different delivery mechanism, namely 'reading through online'. For many years, especially in the West, there have been doubts whether the written medium of narration would survive the onslaught of technology. We also wonder as to whether children and adults who spend most of their time in front of a television or computer continue to read books. In what seems to be a response to this, Aina et al observe that similar fears were expressed at the end of the 19th century, with the emergence of films and cartoons. Books survived that era and maintained their position as a parallel "technology". This observation, therefore, seems to echo the need today for the integration of book reading with high tech, that is, the integration of multi-media activities such as photography, printing and drawing, sewing and crafts, 3-D and digital art, hip-hop, and online services in our libraries. This will help in reversing the decline in book reading among children and adults. ${ }^{5}$ Oke appears to provide an observation that is crucial to this study when he contends that 'a conscious effort should be made by all stakeholders in the educational system to promote the reading habit'. According to him, equipping libraries is the first practical step in this effort. ${ }^{6}$

Finally, scholars have also looked at factors that hinder people from acquiring good reading habits, especially in the sub-Saharan Africa. Among the factors cited by Aina et al, the following are crucial to this study.

Poverty: In sub-Saharan Africa, the impact of poverty is deeply felt. Only a few people live above the poverty line. About $80 \%$ of Africans live under hazardous conditions, with as low as two dollars per capita income in most sub-Saharan countries. This, in no little measure, affects the reading habits of people. Many are too poor to send their children to school. They lack money to buy books and pay school fees.

Corruption: Corruption has a profound effect in many African countries. In most sub-Saharan countries, corruption drastically affects citizens everywhere from government institutions to private organizations, despite much effort made in fighting it. In schools, for instance, many students prefer to indulge in immoral acts rather than face their studies diligently. Situations like trading sex for grades, sales of ungraded textbooks to students at high fees, using money to buy examination grades, and cheating in examinations abound in institutions of higher learning. Those who engage in these infamous acts consider reading a waste of time. 
Lack of Reading Language: In many homes, the language of reading is introduced late; the first contact point of some children with this language is in school. As children grow older, reading and its associated activities become herculean.

Dearth of Libraries: Libraries play an important role in the promotion of reading habits. However, these libraries (school and public) are either non-existent or not playing their expected role. State and local government and proprietors of schools do not comply with library provisions in the National Policy on Education. Public libraries are not being established where they are needed.

\section{Methodology}

The data were collected by using questionnaires and in-depth interviews from a sample of 210 informants comprising 197 undergraduate students and 13 lecturers, all from Kwame Nkrumah University. The students were chosen randomly at the university campus during their August 2016 residential school, while the lecturers were selected using Purposive (judgmental) method.

Both qualitative and quantitative methods were used. Qualitative method was used to collect information pertaining to opinions and views of the respondents and quantitative method was used to collect statistical data. Purposive method was applied on lecturers because of the predetermined nature of information that was required from those with a training background on literacy, as well as those deemed to have special knowledge on principles of Distance Education. The questionnaire was designed in such a manner that it provided spaces for both quantitative and qualitative data. Questionnaires were personally distributed or administered to the students.

\subsection{Data Recording and Analysis}

Content Analysis Method was used in the recording and analysis of data. By way of content analysis, the text (data) was systematically converted to numerical variables for quantifiable analysis. This method enabled me to examine the primary data from the questionnaires. Here the recording and analysis of information that was gathered was preceded by the designing of a special "path of analysis' (or simply a description). The preparation of data for analysis involved coding, where the analysed material was classified into various codes, for example, using different numerical values for different types of answers from respondents. In coding, the main option to be considered was the Inductive Approach because of much qualitative information that was involved in the study. This entailed the classification of information at the end of data collection. There was not much calculation needed in this approach. The making of inferences was however vital and this was purely logical and entirely my task.

To some extent, Informal Method was also applied in the data analysis, owing to the varying nature of information that was sourced by the study where. This was applied to those forms of data that simply needed informal quantification method, for instance, in the process of examining such things as repetitive or patterned behaviour. One procedure followed by this study depended on the frequency of something occurring. In a case where a phenomenon occurred very frequently, I omitted some reference to it to avoid repetition. This of course, relied on counting frequencies to determine which data should be omitted. Frequency was also used to determine whether an action or event normally happened or whether it was a rare occurrence.

\section{FINDINGS}

\subsection{Age Range of Respondents}

Most of the respondents (91\%) were young adults aged between 20 to 40 years, with only few (9\%) in the middle age category. There were neither teenagers (aged below 20 years) nor the 'Aged' in the sample. In terms of gender, the sample constituted $27 \%$ males and $73 \%$ females, the majority of whom $(57 \%)$ were urbanites and $43 \%$ were rural dwellers.

\subsection{The Reading Habits of Students}

On the question that asked whether students enjoyed reading books in general, 89\% said they did while the $11 \%$ said they did not enjoy. Those who enjoyed reading advanced a number of reasons to justify their habit. Most of them said they read in order to gain more knowledge, followed by those who simply read for academic purposes. The latter category included those who merely wanted to improve on their grammar, reading skills and research skills. 
The third category consisted of students who read for spiritual satisfaction. This category mainly utilised religious literature which, according to them, contained powerful hidden knowledge that helped to reduce their tension in what they considered as the current stressful life. They, therefore, mainly read religious literature for their spiritual edification.

Those who read for entertainment constituted yet another category. These mainly read thriller novels and story books. They often read such kind of literature for leisure, as a recreational activity.

There was also another category of those who read in order to discover new things about this world. They had an advantage of being kept updated on new developments in the global world. Besides, reading broadened their understanding of issues in general and, therefore, developed in them wider concepts of things they knew little about. Since, as students, they were expected to be critical in their exposition, reading in this regard helped them in making informed decisions in life, even outside school. Since they read for general information, this category did not have a favourite literature. For them, reading was just a hobby.

On the other hand, those who said they never enjoyed reading had their own reasons to advance. Some simply said they had little or no interest at all in reading, while others said they were just too busy for books. As for the latter, involvements in various home chores and heavy workloads from their places of work deprived them of the time for reading. There were also some who placed the blame on forces beyond their control, such as the lack of access to reading material, having been brought up from poor reading backgrounds, et cetera. This was often the case with those students who either came from rural areas where there were no library facilities or those from urban places with poorly stocked libraries. Other reasons given were: reading not being a hobby, too much watching Television at home, health problems (such as poor sights) or simply laziness. During Residential School ${ }^{7}$ this category of students only read books that were prescribed in their respective courses, under what they described as a difficult coercive measure just to enable them pass exams.

\subsection{Reading (of Modules) at Home}

Eighty-four per cent $(84 \%)$ of the students said they consistently read the modules at home while the sixteen per cent (16\%) said they rarely or did not read the modules at all. While at home, students read the module for varied reasons. Most of them read for academic reasons, to prepare for examinations while others read in order to reinforce on what had been taught during the previous residential schools. Keeping in tune with school work, avoiding panicking during residential and taking advantage of the abundant time at home were other reasons that motivated some students to read at home, apart from simply reading for more knowledge. A good number of students in this category said modules provided them with the necessary guidance during their studies in their respective courses, apart from merely being the source of content. They as well praised the initiative by the university to form study groups in various provincial centres which they said had motivated them in their studies while at home.

Students who seldom read the module at home cited the pressing responsibilities at their respective workplaces as having deprived them of the precious reading time. Other hindrances cited were the various home chores and environments that were not conducive for studies, such as noise pollution. There were also other students who cited loneliness, saying they were the only ones studying in the communities they came from, which they said had affected their studies because they had no one to share information with. Others said they did not read at home simply because they were highly influenced by the emerging technologies, citing distractors such as watching movies on Television and on smart phones as their major sources of entertainment, depriving them of their reading time. In a somewhat ridiculous manner, a few students said they did not read simply because they were lazy.

\subsection{Students' Different Opinions on Preferred Reading Environments}

Twenty-eight per cent (28\%) of the respondents had a positive attitude to reading and had contended that they got much of the understanding of their course contents when they read their module alone at home. For them, the home environment was better because it provided plenty of time for reading, unlike the school environment (Residential School). One student said:

Availability of time at home enables me to read and re-read my modules until I understand the concepts. I also have freedom to decide when to read, and study at my own pace which I cannot do during those Residential schools. Besides, I 
benefit much from sharing ideas which we share in simple terms with colleagues during group discussions at home. ${ }^{8}$

Such (the above) were some of the typical examples of responses from students who reflected the home environment in their preferences. Others said they had ample time and higher chances of consulting books and the internet services when alone at home than at campus where the huge number of students scrambled for such resources and services, and where such resources never met the demand. Home was also a better studying environment for those who saw school residential as being characterised by too much pressure from assignments and tests. Due to the nature and short duration of the residential, such students also felt there was inadequate coverage of content hence used the period to get much guidance, as one put it:

During school residential, everything is done hurriedly due to limited time. Some lecturers only give guidance and much understanding of the course content only takes place when I do more reading alone at home. ${ }^{9}$

Others said the residential contact lessons given by lecturers on selected units of the module were not sufficient, which meant that they still needed much time to go through the module alone at home in order to understand the concepts. There were also those who said they concentrated more when they studied alone than in groups and took time to understand, hence could not fully benefit from the short contact lessons during residential. Some still blamed lecturers for not explaining their lessons fully and that in some cases, they were just too fast.

Nevertheless, more students (58\%) claimed to have benefitted much from the school residential in their understanding of the content. They said lecturers gave clear explanations, guidance and elaborations on key concepts in simple terms making topics more comprehensible, especially in those modules which had terminological and language difficulties. They said lecturers also gave new helpful points and insights (other than what was contained in the modules) during contact lessons. Those who came from places without libraries or where libraries were in deplorable state, as well as those who came from communities where they had no other students they could study with, added to the number of those that preferred the school residential. For them, residential period was a rare opportunity they would utilise the library facilities in their research, seize what they termed as the rare opportunity to interact with lecturers and fellow students and seek clarity on concepts they did not understand during their reading at home.

There were yet other factors that contributed to some other students finding it difficult to rely on selfreading at home. One of them emanated from the complaints that some modules were not written properly - that they contained a lot of jargons which made it difficult for students to understand the contents. Some students added that some modules did not contain adequate information required by the syllabuses, which lecturers only gave in more elaborate details during school residential. In short, this category of learners failed to utilise their modules at home to their benefit, unless lecturers were there to guide them and give clarifications on certain concepts. While it was expected of lecturers to offer guidance in this regard, the situation was unique for these students whose attitude to self-reading was simply negative. Among them were those who admitted that they had no time to read on their own at home and could only open and flip through their modules during the two weeks of school residential. Another considerable number of those who did not read the module at home in preference for contact lessons given during school residential based their reasons on personal factors such as:

- I just understand better when someone lectures or explains to me, than when I read.

- I don't enjoy reading, so I depend on lectures

- I don't easily forget what I hear while gazing at someone speaking to me, unlike when I read.

These findings lead to at least one great question: how do students manage to pass in their tests, coursework and final exam given this poor background of not reading the module, or not having interest in reading other books as the case is for others?

\section{Discussion}

The ability to read is increasingly becoming a determinant in acquiring formal education today, especially with the growing need to expand the education provision through the Distance and Open 
Learning mode, a need which has come as a result of the ever increasing demand for education due to population increase. Yet, the results of this study of Kwame Nkrumah University students seems to suggest the poor culture of reading having a bearing on their academic performance.

\subsection{The Poor Culture of Reading Underlay Students' Challenges in Studying at Home}

Students cited a number of challenges which they said they faced in reading the modules at home. They brought out several issues most of which focused on the quality of modules. Most of them complained that they faced difficulties in comprehending the contents of the modules either because of the language or terminologies used by authors. The failure to grasp certain concepts in the modules due to such challenges made some students read the modules with a dictionary by their side. Others could not contain the challenges and simply gave up at this stage, meaning they suspended their reading up until the following school residential session when they could seek help from lecturers and fellow students at the campus. This challenge most affect those students who came from communities where they were the only one studying at Kwame Nkrumah University, hence could not benefit from the study group initiative the university came up with. There were three subsequent problems arising from this challenge identified by this study. The first one was that the two weeks duration of the residential schooling was not adequate enough to enable a student who never studied at home to have a good coverage in reading and mastering the content in a way that was enough to enable him/her pass an exam. The second problem consisted in the caliber of the students themselves. In this case we are talking about students, some of whom had a poor background to self-reading and to whom the best way to learning would be through the contiguous method that allowed an interaction with lecturers. A third problems hinges on the very design of the programme: in this programme the student is expected to interact with the module almost exclusively, in a manner that the module assumes the role of a teacher. The residential schooling which in this case served as a sigh of relief by students who found themselves in such a predicament might not provide adequate reassurance because this period was not meant for that purpose. In principal, much of the focus during the School residential period should be on practical subjects, giving clarifications to students and carry out assessments, unless otherwise. This, however, is in no way to say lectures should not be conducted during school this period, but the point here is that where this happens, it should be counted as an initiative which students should only take as an added advantage.

\subsection{Can Poor Reading Culture Contribute to Students' Dishonest in Acquiring Marks?}

Given the above scenario, one would expect the poor performance by students in coursework and examinations, high attrition rate and low progression rate as subsequent results characterising the education progression. Fearing such repercussions, students resort to other shortcut and illegal means to make it in academics such as involving themselves in exam leakages, buying of marks from lecturers, engaging in promiscuity through what is locally referred to as 'use of bottom power' where female students sell sex to male lecturers in exchange for grades, use of nepotism in negotiating for marks, et cetera.

The report of the survey conducted between February and November 2016 by the Transparent International in Rwanda revealed that several female students in Universities get free marks from their lecturers in exchange for sexual favours, calling into question the credibility of some of the graduates entering the labour market. On male students, the report added that some students get good grades that they do not deserve because they either buy alcohol or give gifts to their lecturers. ${ }^{10}$ Where as some of the students who are involved in these schemes do so deliberately, others are caught up in situations where they think that it is only conniving with lecturers in obtaining grades that they can pass. In the Distance Education programme, we are mainly referring to the kind of students whose tight schedules at their places of work already deprive them of their precious time to read. The situation just becomes worse for those students with poor reading habits.

The revelation of the above report seems to be a replica of what transpires in many African Universities, Kwame Nkrumah University inclusive. In confirming the prevalence of the menace at one of the renowned Universities in Zambia, one lecturer interviewed in this study cited an incident where a lecturer undertook a research project for a female student and compiled the findings for her.

Nepotism: Among the acts of dishonest students find themselves in is nepotism. This involves students using power or influence, or taking advantage of relations with some members of staff in the university, in the negotiations for favours with course lecturers. 
Cheating in Assignment Writing and Leakages in the Exams: Students with poor-reading back ground are more likely to find it difficult when it comes to writing assignments owing to their failure to read, which makes it practically difficult for them to undertake research as well. In their desperate efforts to pass in their Continuous Assessments, ${ }^{11}$ some resort to using dishonest means such as submitting duplicated assignments and hiring the services of other people in the writing of assignments. Such seemingly 'petty' cases of dishonest have occasionally surfaced at Kwame Nkrumah University. A dean in one of the schools, for instance, narrated a case involving two students submitting similar work where the contents in both papers matched word-by-word, as well as in punctuation marks and writing style. The only difference was the particulars of candidates. As regards the hiring of services in assignment writing, a conspiracy was recently exposed where certain individuals had strategically positioned themselves at some places in town away from the campus during residential school, and secretly advertised their services. They had offered to write assignments and project proposals on any topic on behalf of students, at quite substantial amounts of money.

This poses a great worry on academicians and educationists who are concerned about the quality of graduates colleges and universities are offloading onto the labour market. This is because students who graduate through such corrupt means use their first class degrees to secure some of the best jobs in the public and private service. Interviews with 'seasoned' members of staff at Kwame Nkrumah University further revealed selected cases of former students from the institution that could be cited as examples, whom today serve in sensitive positions such as Secondary School managers and lecturers at tertiary institutions of learning.

I therefore contend that some of such dishonest acts students use in acquiring marks are a result of the panic caused by not being adequately prepared at home in terms of reading, causing them to depend on the little time available for them at the campus.

This article, therefore, challenges those involved in the advocacy in the deterioration of the reading culture to recast their view on the menace and begin to see things differently. It is not enough to have mere politically motivated rhetoric aimed at raising literacy levels of Zambian citizens (especially children) through imparting basic skills in reading and writing. But there is need to nurture these skills if we are to have the country's citizenry with sound reading culture. This is not a job to leave to politicians alone, but one in which educationists and academicians need to play active roles. There is need, therefore, for concerted efforts between educationists and academic moral advocates to address what I call the 'celebration of mediocrity'; a tendency where corruption is tolerated in the awarding of marks to students, which has seen the undeserving-low caliber students graduate smoothly and see themselves through to the labour market unchecked. The demoralising effects this poses to their counterparts who are the deserving, hard-working and intelligent students, and who strive to excel on grounds of merit is quite huge and unfortunate. In this article, I contend that the 'celebration of mediocrity' as viewed in this context, directly or indirectly contributes to the waning of the reading culture in the very sense that it possibly influences those in the poor habit of reading into creating a comfort zone in their situation, thinking after all, alternative (illegal) avenues are available which can easily be utilised in their desperation to pass the examinations, and eventually secure themselves the best jobs on the labour market. This vice could have further been encouraged by the unfortunate seemingly shifting paradigm in education today, where 'education for certification' seems to take the centre stage at the expense of the 'education for knowledge' in many institutions of higher learning.

\subsection{Reconsidering the Role of Libraries}

Dealing with the challenges that emanate from the students' poor reading background as revealed by this study requires a multifaceted approach. Addressing the issues discussed above, such as corruption, exam leakages, promiscuity and all manner of illegalities or dishonest prevalent among students and lecturers in higher institutions of learning may on its own not be good enough. I propose to begin from the roots, for instance, to look at the issues of libraries.

Though currently the libraries in Zambia may have been considered an integral part of the educational development, most of the available public libraries in most towns our students come from seem not to have been efficiently supported. As such, they are either in deplorable conditions or insufficiently equipped with necessary materials. For students in rural areas who may only rely on the school libraries owing to lack of public libraries, the story may even be worse. 
In this article, I contend that the role libraries play in one's reading culture should not be underestimated. Libraries provide resources that offer more extensive and varied information that can serve to supplement what goes on in the classroom. This includes among others, the conducive environment required in the reading for information, reading for pleasure, studying for examinations, and reading for personal growth. Such environment is also critical in developing the habit of voluntary reading in an individual, which in turn helps develop reading skills. We take a leaf from countries such as Nigeria whose National Policy on Education has deliberately recognised literacy and numeracy as basic tools for personal and national development, and ability to communicate effectively as one of the objectives of school education. ${ }^{12}$ In such countries, the role of the libraries has been considered crucial in attaining educational goals. Besides, the role libraries play in promoting reading is especially crucial in developing scientific, reflective thinking and creativity. Librarians can also help students develop critical and independent thinking through their exposure to a wide variety of instructional resources and learning opportunities. Apart from the development of creative and critical thought, the role of libraries in the promotion of reading culture can be seen in the readers' development of values, attitudes, and appreciation, skills and mastery of language. Libraries also help in extending learners' knowledge, and assist them in their academic work. Learners who read are likely to have background knowledge, familiarity with new topics or subjects, and thus, find learning easier and interesting. ${ }^{13}$

\section{Conclusion}

In this article, I have examined the effects of poor reading culture among the Distance Education Students at Kwame Nkrumah University in Zambia. I have noted that though in principle the delivery of courses for Distance students at the institution has been done through the distance mode, there has also been some kind of Contiguous (face-to-face) mode, as the case is during residential schooling. In this mode of learning, students mainly learn through modules. This article, therefore, regards one's ability to read and his /her comprehension skill as crucial requirements if one is to make it through distance learning. The central contention in here is that a sound reading culture is an essential prerequisite in any student involved in a form of learning that makes use of modules.

The claim that there has been deterioration in reading culture among the Distance Education students at Kwame Nkrumah University has been assessed, and the effects that arise as a result of this have been determined. The article has, therefore, revealed that there were more students who had preferred the Campus-based residential school sessions to self-read at home, and most of whose justifications and challenges pointed to their poor reading backgrounds. They gave varied reasons ranging from not understanding certain concepts, general negative attitude to reading, laziness, reading not being a hobby, et cetera. The article has further analysed the possible factors that could have contributed to such poor reading habits, which basically hinge on lack of concerted efforts by key stakeholders in the promotion of reading (i.e. government, Non-governmental Organisations and institutions of learning), failure to reposition, and poor support to the role of libraries in the nation.

In addressing the problem of corrupt, indecency and dishonest means students use in exchange for academic favours from lecturers at higher institutions of learning and Kwame Nkrumah University in particular, I suggest that a fair amount of energy be exerted to pointing out to the need to consider the causes and effects of poor reading culture of students on their academic performance as well. This is not only because we need to raise the country's population to a certain level of literacy or wish to attain one of the requirements of the Millennium Goals on universal education, but also because, as this article has laboured to explain, it will contribute to mitigating the prevalence of the above mentioned vices in higher institutions of learning.

\section{RECOMMENDATIONS}

Libraries in Zambia should provide access to reading material through which learners can gain and improve their skills. In so doing, they will create enabling environments to learners who seek reading for information, pleasure, passing examination, and personal growth through life-learning. Library in Zambia should, therefore, provide materials that offer more extensive and varied information than what a classroom can do.

The Zambian government, through ministries of education should recognise literacy as a basic tool for personal development. As such, it should formulate deliberate national policies on education for its citizens, aimed at inculcating the ability to read and communicate effectively, among objectives of school education. 
The government of Zambia should encourage the bringing on board of the Non-governmental organisations (NGOs) that wish to sponsor readership campaign programmes as a deliberate effort and strategy to ginger-up the culture of reading in the country.

\section{REFERENCES}

[1] Lewis, R. and Spencer, D. (1886). What is Open Learning? Open Learning Guide 4, London, Council for Educational Technology, pp. 9-10.

[2] Henry, P. (2004) "Children reading habits and their use of media: Exhaustive Suggestions on Encouraging Reading Habits among Children". (e-journal). Paper 529. Nigeria: Lagos State University.

[3] Aina, A. J. et al "Poor Reading Habits among Nigerians: The Role of Libraries". (2011). Library Philosophy and Practice (e-journal). Paper 529. Nigeria: Lagos State University.

[4] Okebukola, F. O. (2004) "Reading: key to lifelong development". A key note address delivered at the workshop on readership promotion campaign organized by the National Library of Nigeria.

[5] Oke, E. (1996) "Analysis of Progress made by Public Libraries in Nigeria" Nigeria School Library Journal 2(4)

[6] Ibid.

[7] This is the time at the end of each term when all Distance Education students report at the main University Campus for assessment purposes. During Residential School, students also consult their course lecturers on areas they found challenges during their studies at home.

[8] Interview with Student X., Kwame Nkrumah University Main Campus, August 9, 2016.

[9] Interview with Student Y., Kwame Nkrumah University Main Campus, August 9, 2016.

[10] The East African Social Media: < http:www.theeastafrican.co.ke/Rwanda/News/lecturers demanding sex >.Retrieved: January 7, 2017.

[11] At Kwame Nkrumah University, a student must pass in a Continuous Assessment which includes assignments and tutorials, given during the term and end-of- term test with at least a weighted average of 40 per cent in the whole coursework in order for him / her to take an examination at the end of an academic year.

[12] Federal Republic of Nigeria (2004) National Policy on Education, 4 th ed. Lagos: NERDC Press.

[13] Library Philosophy and Practice (e-journal), DigitalCommons@University of Nebraska -Lincoln

\section{AUTHOR's BIOGRAPHY}

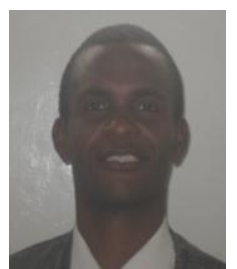

Dr. Joseph Kayuni Hachintu, holds a PhD (DLitt et Phil) and a Master Degree in Religious Studies both from University of South Africa, and a Bachelor of Arts with Education (Religious Studies and Special Education) Degree from University of Zambia. He taught briefly at a High School in Mpika and served as District Education Planning Officer for Isoka District in Zambia for four years before joining Kwame Nkrumah University where he served as Senior Lecturer in the Department of Religious Studies for eight years. He is formerly Head of Quality Assurance Department and currently the Acting Director - Directorate of Research and Graduate Studies at Kwame Nkrumah University. Dr. Hachintu has published a number of articles, some of which have appeared in International Journals. His main research interests include Religion and Society, Education and Society, Sexuality, HIV/AIDS and Quality-Education Delivery. 